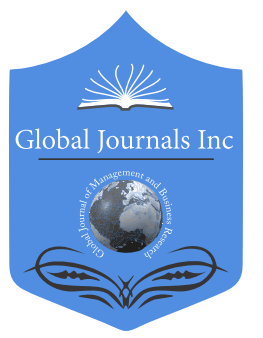

\title{
Business Ethics for Global Sustainable Quality Generation in Organisations: Proposing the "BESQ" Scale
}

By Dr. Partha Naskar

Abstract-Background: Business ethics is the doorbell in management literature and for business houses today. The essence of human values is quite pertinent for long term sustenance of organizations. Understanding business ethics and its relevance in recent times is the most calling global challenge across organizations. The objective of the study is to explore and investigate the prominent domains and items that may be considered on the relevance, applicability and rationale of business ethics viz. Domain A: Employee Goals for Business Ethics, Domain B: Diversity Management, Domain C: Entity Value on Decision making, Domain D: Legal Perspectives of Business, E: Diversified Ethics with Gender Differentiation. The paper ultimately aims towards developing a scale for finding conclusive remarks in certain identifiable areas within the field of Business Ethics. The main source of conceptualizing the domains is formulated with related literature and the Experts opinion comprising both academicians and practicing managers in the industry in Kolkata as well as across the country through primary and secondary collection methods.

Keywords: ethics, business, sustainable, quality, scale.

GJMBR-A Classification: JEL Code: M19

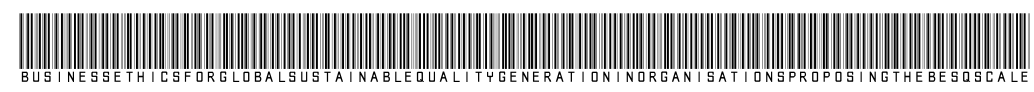

Strictly as per the compliance and regulations of:

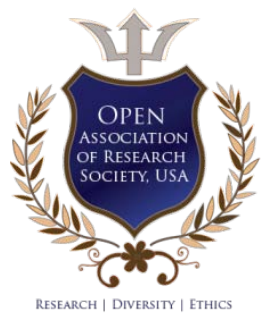

(c) 2020. Dr. Partha Naskar. This is a research/review paper, distributed under the terms of the Creative Commons AttributionNoncommercial 3.0 Unported License http://creativecommons.org/licenses/by-nc/3.0/), permitting all non-commercial use, distribution, and reproduction in any medium, provided the original work is properly cited. 


\title{
Business Ethics for Global Sustainable Quality Generation in Organisations: Proposing the "BESQ" Scale
}

\author{
Dr. Partha Naskar
}

\begin{abstract}
Background: Business ethics is the doorbell in management literature and for business houses today. The essence of human values is quite pertinent for long term sustenance of organizations. Understanding business ethics and its relevance in recent times is the most calling global challenge across organizations. The objective of the study is to explore and investigate the prominent domains and items that may be considered on the relevance, applicability and rationale of business ethics viz. Domain A: Employee Goals for Business Ethics, Domain B: Diversity Management, Domain C: Entity Value on Decision making, Domain D: Legal Perspectives of Business, E: Diversified Ethics with Gender Differentiation. The paper ultimately aims towards developing a scale for finding conclusive remarks in certain identifiable areas within the field of Business Ethics. The main source of conceptualizing the domains is formulated with related literature and the Experts opinion comprising both academicians and practicing managers in the industry in Kolkata as well as across the country through primary and secondary collection methods. A Scale would be created involving essential considerations of the paper with the identifiable Domains. These would be considered as independent variables and the notion of Business Ethics and Sustainable Management practices as dependent variables. The creation of the scale, in this paper would involve identification of the items within the scale using literature review as essential basis. The paper upholds an attempt to create the "Business Ethics for Sustainable Quality"- "BESQ" Scale with its domains and items within with a focus on business ethics as a gateway to global sustainable organizational development. The implication of the study is that it throws considerable light on the impact of business ethics as quite relevant for continual progression for present day organizations. The drafted scale may be referred in similar studies in future in primary research work in this area.

Keywords: ethics, business, sustainable, quality, scale.
\end{abstract}

\section{Business Ethics: Lessons \& Prospects}

$\Lambda$ midst waves of social uncertainties and business fluctuations, the navigating force behind strong governance vests on value education scripted through exploration, learning and co-curricular activities focusing on the ethical way of life. The sphere of industry driven by the individuals is the congruent of ethical culture directed in the cultivation of moral values enriched with the system of ethical knowledge Author: Additional Pay \& Accounts Officer Kolkata Pay \& Accounts Office /l Finance Department, Government of West Bengal.

e-mail: naskarpartha@yahoo.co.in mechanism. The initialization of ethical outlook gears up with the hub of data disseminated in the form of journals, research papers, books covering ethical issues, moral integrity and ethical decision making. The light of ethical synchronization, uniformity and fairness are seen to be ignited within the inner instinct of the learners with reasonable understanding, justifiable opinion and sense of belongingness. The close intermediary forces underlying any business environment rests on manpower surrounded by society at large. The nucleus of Business-Government-Society is the core of every ethical structure prevailing across the boundaries. The essence of realistic view in the ethical court of righteousness creates a consciousness among the prospective aspirants of business and management. The bible of ethical codes are seen encrypted within the bounds of moral approach reflecting the key regions of ethical challenges, narrating the significance of ethical integration and visualizing the true spirit of ethical discipline. The culmination of national ideals with international views speak of the notion of east meets west through a consequential empirical approach translating the 'Kautilya Code' in the words of Weber. The choice of appropriate academic curriculum designed with ethical methods of selfassessment, attitude building frameworks and right conduct rules conducive for institutional ethical elevation all constitute a perfect equilibrium between business operation and holistic perspective of ethical responsibilities. The ethical pillars of value and wisdom depicted in the Buddhist architecture and scriptures interpret welfare of the community coined in today's world as Human Development projecting and promoting the 'good' and 'goodness' - the key words of global ethical transcript (Brenner, 1992).

\section{Establishing Ethics}

In the last two decades the waves of several visible trends and attitudinal changes have been reflected in the management thoughts emphasizing on eternal human values. The timeless treasure of 'sanatana' that which never perish continues to inspire humanity as captured by the famous verses from Gita 'Yadayada hi dharmasya' signifying whenever there will be a decline in the human values there will be dharma or 
the morality to revive human values. With the flow of time, the essence of human values seem to be nurtured within the shell of Human Resource Management synthesizing a holistic view of life, touching the spiritual heights with material attainment. The new millennium of $\mathrm{HR}$ practices gives a futuristic look of human values in the name of 'Ethics'. "All HR practices have an ethical foundation. Human Resource deals with the practical consequences of human behavior". Business Ethics also termed as corporate ethics is a form of applied ethics or professional ethics that examines ethical principles and moral or ethical problems that arise in a business environment. It applies, to all aspects of business conduct and is relevant to the behavior of the individuals and entire organizations (Kumar, 2003).

It is quite pertinent that care should be taken that individuals, groups and teams learn to value work with ethical behavior within their operational responsibilities in the workspace. In other words businesses need to harp upon creating a ethical culture and climate where employees find and feel rightly occupied for qualitative outputs at work. In this paper, the essential objective is to delineate the notion and rationale of business ethics for sustainable quality generation along the lines os specific consideration. These considerations would be terms of the focal issues of discovering goals \& ethics, diversity management and ethics, entity value on decision making, legal perspective on business ethics and diversified ethics and gender differentiation. The idea of the paper is to connect these elemental considerations to rationalize their criticality towards building sustainable ethical standards within organizations. The aim of the paper is to identify the items that may be considered "BESQ" Scale.

\section{ili. Research Methodology}

The study would be based on secondary literature survey. A scale would be created involving the essential considerations of the paper viz., discovering goals \& ethics, diversity management and ethics, entity value on decision making, legal perspective on business ethics and diversified ethics and gender differentiation. These would be considered as independent variables and the notion of business ethics for sustainable quality generation as dependent variables. The creation of the scale, in this paper, would involve identification of items within the scale, using literature review as the essential basis.

The structured scale would be the research instrument with clear nomenclature of "BESQ" Scale, towards collection of primary data and feedback for future scope of the study; "B" meaning Business, "E" meaning Ethics, "S" meaning Sustainable and " $Q$ " meaning Quality.

\section{Literature ReVieW}

\section{a) Rediscovering Goals \& Ethics}

The all-encompassing angles of direction constantly indicate the roadway to reach the goals of attainment. Realization of individual self-merged with ethical ideologies creates a significant impact in the accomplishment of desired organizational goals. The exploration of the twin wings of idealism \& relativism establishes bondage of ethical principles tied with trait goal orientations (Urdan, 1997). An interconnectivity relationship between idealism-relativism-trait goal orientation-ethical dimensions is being drawn in the in Figure 1, which postulates that goal oriented behavior is an inevitable phenomenon in the analysis of ethical orientation.

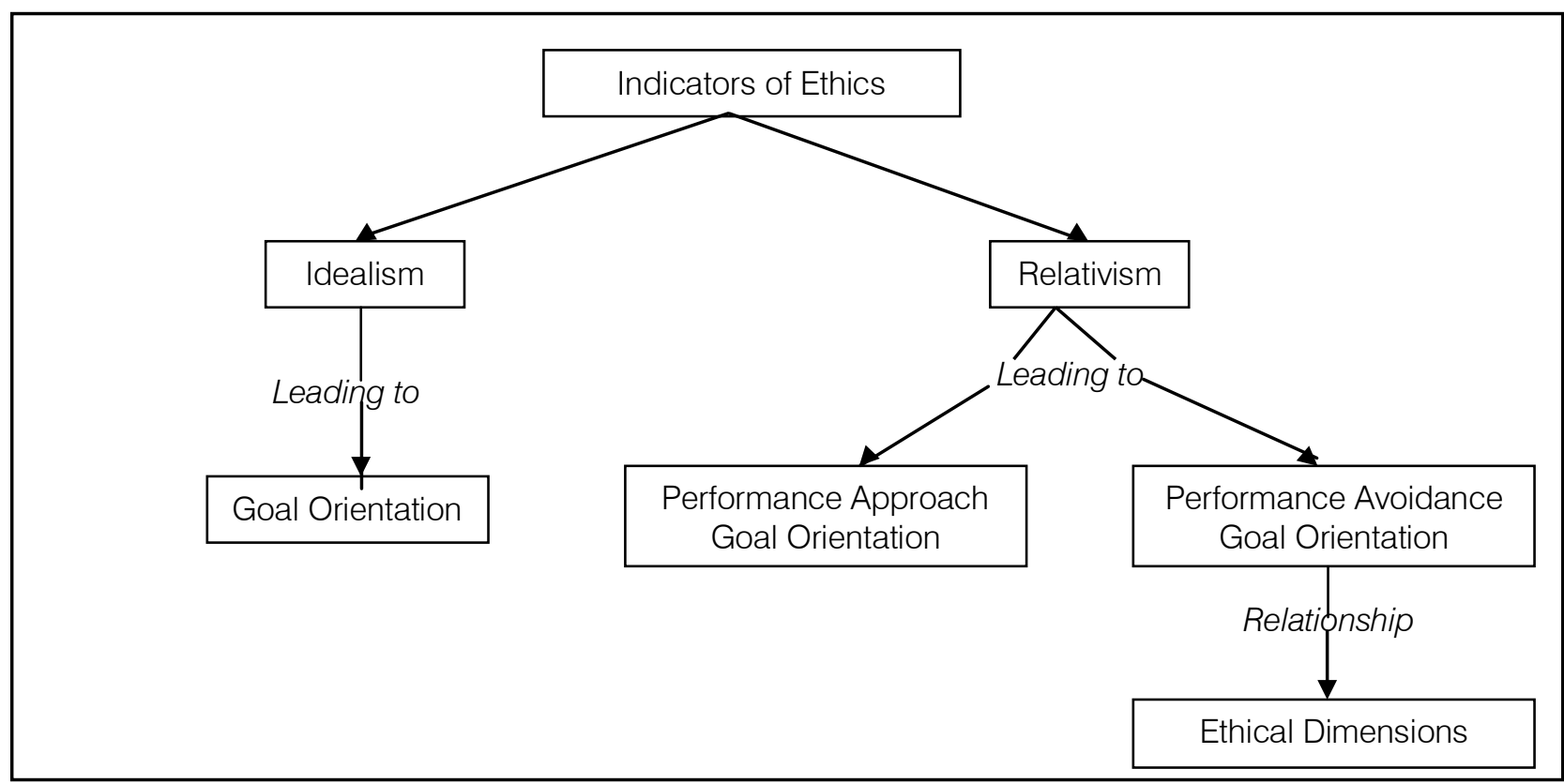

Figure 1: Roadway to Ethics \& Goal Orientation 
In order to bridge the gap between individual beliefs and set of standard norms coined as individual goal orientation and ethical ideologies, three broad parameters can be drawn to build connectivity with potential -personality and ethical-worth. The foundation of relationship integration is erected on Ethical Ideologies, Goals \& Ethics and Goal Orientations - all lying on the motivational plane of relationship is illustrated in the given Figure 2.

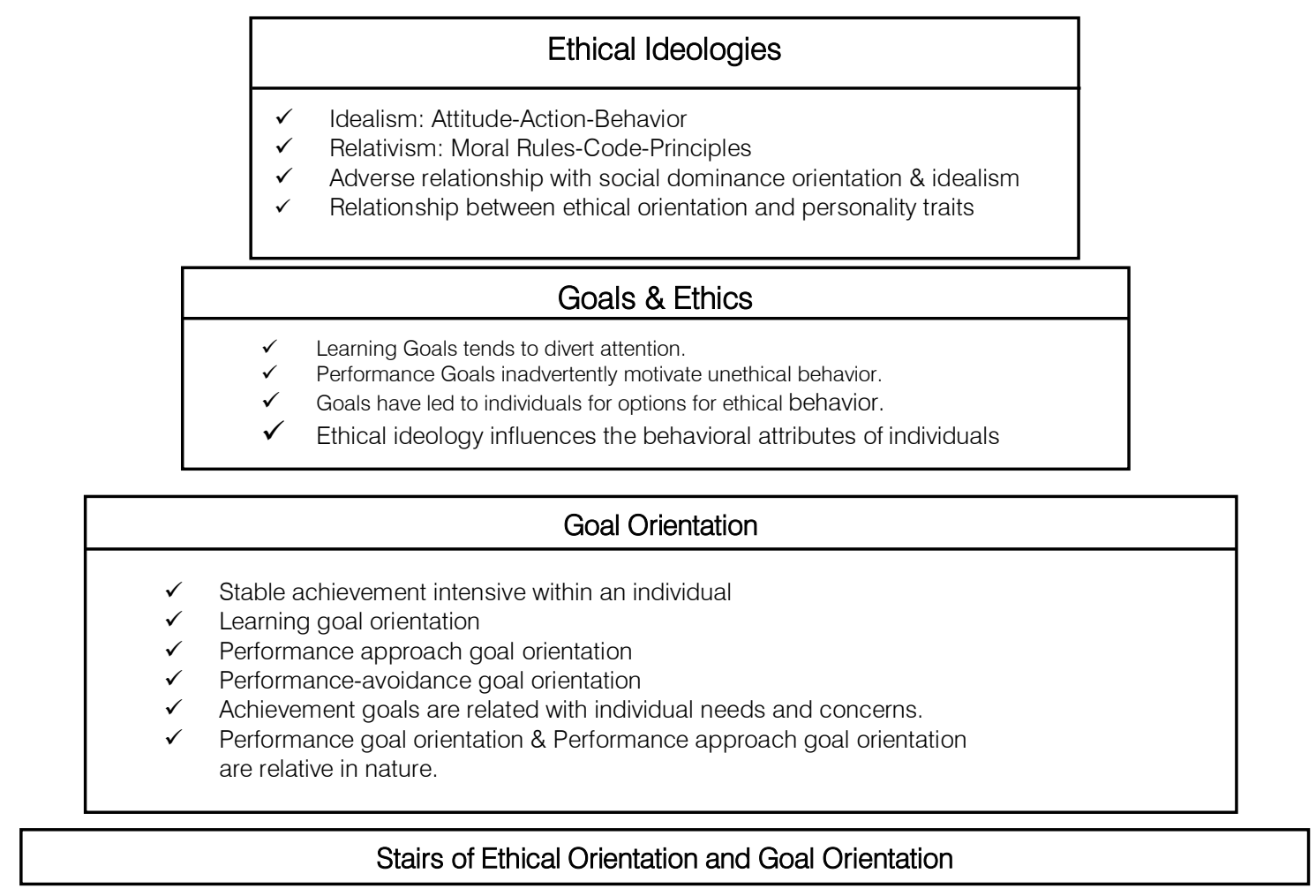

Figure 2: Orientation redefined though Ethics and Goals

\section{b) Diversity Management and Ethics}

The urge for excellence at the organizational ground is deeply rooted with human elements yielding crops of efficiency and productivity. A perfect blend of diversified values and potentials creates a sound working climate for the non-profiled work force contributing optimum outcomes in the qualitative and quantitative magnitudes. The scale of competence propounded by the ethical principles encourages the functional level of the executives in the organizational hierarchy. Appreciation of human ability, gratification of human rights and acknowledgment of human preferences are the key essentials of Diversity Management wherein ethics and productivity are merged with each other regardless of gender, age, religion, nationality and culture. The search for proficient human skill and its fair and equitable recognition in the diversified situations has become a difficult task for the executives. To get acquainted with others, to share the emotional state of mind, to understand the feelings -all amalgamate into the streams of diversified human actions supplemented by righteous decision making showcased as ethical soundness and fostering growth and prosperity. In spite of disparity in compassion, the recognition of the employees at times are assessed on the basis of performance versus potentiality. The exigent work forces need to be exposed through support, learning and collaboration. Managing diversity skills is an endeavor to pursue all work-groups of both genders to appreciate the energizing, creative, idealistic and rational body of collective human forces. In the colliding steps of individualistic views, profile, ethics and culture this diversity needs to be balanced reasonably so that the willing members feel a sense of equity in minimizing stress and maximizing employee productivity at workplace (Gentile, 1998).

\section{c) Entity Value on Decision Making}

The selection of proper course of action out of abundant available alternatives demands correct assessment based on perfect judgment device. In the organizational zone of actions the collective values of the managerial squad acts as a predictor of human resource decision-making. An individual self-esteem takes the shape of a valuable component in the thought process of organizational operations. The worth of individual entity gets transformed into group integration and touches the feat of organizational value under the framework of human resource verdict. The ingredient of 
ideals, preferences, attitudes, viewpoints make the value element as the most unique and enduring. Originating from the human mind, the life-line of human values confronts hurdles of divergence and dilemmas, share harmony of mutual collaboration and acquire the accepted value structures all motivating the managerial behavior in the context of a judicious decision making situation. Feasibility of value in the perspective of traditional approach or the rational focus of value plays a significant position in the individual and managerial decision-making processes (Gibson \& Gamble, 1999).

Individual values have undergone transition with resistance and fear of cultural differences, inclination towards authentic peer behavior, prominence on teamwork over in-house contest and shift from avoidance to facilitate the productive expression. The wide array of HR decision-making issues is very well associated with the component of human value, the magnitude of which cannot be ignored or be overemphasized to sustain reasonable balance between the human factor and organizational expectations.

\section{d) Legal perspective of Business Ethics}

The ever-increasing complexities in the competitive market have multiplied its density in recent years. The progression of growth has joined hands with irregularities complemented with increasing unethical behavior among the participants of the corporate province. Every action attributed towards the welfare of people must be evaluated on the scale of translucent yardstick formulated by rules framed from time to time.
The set of rules integrated within the legal edge acts as a protective and defending shield against all created immoral course of actions which is detrimental for human advancement. Corporate rules appended with ethical parameters govern the moral outlook and righteous way of business functioning (Linda et al, 1999).

Any code of conduct followed unanimously by the individuals at different situations are considered as statute and commonly accepted as 'Rules'. The fundamental spirit underlying any business rules comprise of truthfulness, integrity and ethical conduct in handling professional and personal relationships added with full, fair and accurate disclosure of reports with adherence to government rules and regulations. The rules are not solely confined to do's and don'ts but commands, delivers and guides all acts ranging risks to returns. A tree will be regarded as beneficial when it yields fruits for human survival and so is the nature characterized by the rules where its applicability and acceptability is included in the plane of ethical decision making. The accord between rules and ethical principles is stringed through the ethical decision process as identification of ethical issue, giving ethical verdict, initiating ethical performances, execution of ethical behavior as the aspects of ethical decision-making in real terms (Near \& Miceli, 2001). This is depicted in Figure 3.

\begin{tabular}{|c|c|}
\hline $\begin{array}{l}\text { Identification of Ethical issue } \\
\text { - } \quad \text { Level of social development } \\
\text { - } \quad \text { Unawareness of others involvement } \\
\text { - } \quad \text { Remoteness from the affected people } \\
\text { Deliberate minimization of Ethical act. }\end{array}$ & $\begin{array}{l}\text { Making the Ethical Verdict } \\
\text { - } \quad \text { Reason influenced intuition } \\
\text { - } \quad \text { Social interaction } \\
\text { Process of improvement }\end{array}$ \\
\hline $\begin{array}{l}\text { Initiating Ethical Performances } \\
\text { - } \quad \text { Autonomy } \\
\text { - } \text { Reactions } \\
\text { - } \quad \text { Justification } \\
\text { - }\end{array}$ & $\begin{array}{l}\text { Execution of Ethical behavior } \\
\text { - } \quad \text { Clear cut intention } \\
\text { - } \quad \text { Transparent action } \\
\text { - } \quad \text { Compliance with rules } \\
\text { - } \quad \text { Expediting Ethical requirements }\end{array}$ \\
\hline
\end{tabular}

Figure 3: Four Quarters of Ethical Sphere

\section{e) Diversified Ethics and Gender Differentiation}

The tale of Adam \& Eve commemorates the episode of humanity that both gender identities are inevitable and indispensable resources in creating the future, nurturing the past and believing the present in the accomplishment of the desired goal. The unified integration of 'man-woman' at times segregates themselves through the varied medium in terms of knowledge, psychology, attitude, biological attributes all landing into the soil of discrimination and difference. The existence of divergence opens the doorway to variable ethical behavior in the organizational hemisphere. The age old tyranny of womanhood gets decomposed underneath by the social stigmas propounded and promulgated through the firm hands of man in the soil of living beings. In spite of the multi- 
faceted role played by the women in the functional contribution of the globe, still the vacuum of tolerance remains imbalanced as the psychological constraints restricts the acceptability of women at the intricate layers of ethical understanding. The wall of difference between men and women remains shielded with social discrimination, mental dissonance and cultural conflicts. On the threshold of twenty-first century there is no reasonable argument to justify the age old disagreement for such inequality. The dimensions of outlook, behavior, views all culminate in the ever flowing waves of culture in the ambit of ideals, values, beliefs and aspirations. An upbringing of a child completes its journey to manhood or womanhood when the pillars of values disseminate through family, religion and social bodies. The building bricks of ethical foundation have its base seeded within the intelligence and mind of men and women which confronts conflicting situation bounded by prejudices, tradition and philosophy. In spite of diversifications in the system of lives, the disparity and dissimilarity seems natural, the unequal instinct gets recognition and distinctive attitudinal attributes are acknowledged in the arena of corporate culture and ethnicity (Gordon \& King, 1998).

Table 2: Relating International Ethical 'Entities-Environment-Emergence'

\section{f) Business Ethics in International Organizations}

The sustenance and the passion of institutions spread worldwide in the land of profitability and productivity are brought together under the unified umbrella of global code of ethics. The defined codes of ethical manual guides, directs and motivates the multinational bodies to elevate into the superlative platform of organizational culture. The mounting business trends encompassed with ethical understanding promotes and recognizes the essence of ethical diversity in the international arena. To combat with the rising corporate scandals among the trading organizations, ethical governance acts a building force for observance and maintenance of vigorous regulations designed with effective decision making mechanism and ethical values. The cross cultural relationships of various business entities within the prevailing climate and the possibilities of ethical dilemmas can be visualized from the ethical image existing at the core of global business practices (Near \& Miceli, 2001). This is illustrated in Figure 4.

\begin{tabular}{|c|c|c|c|c|c|c|}
\hline \multicolumn{7}{|c|}{ Ethical Phenomenon } \\
\hline \multicolumn{3}{|c|}{ Entities Issues } & \multicolumn{2}{|c|}{ Environment } & \multicolumn{2}{|c|}{ Emergence ${ }^{\text {Outcomes }}$} \\
\hline OECD & \multirow{5}{*}{\multicolumn{2}{|c|}{$\begin{array}{ll}\text { - } & \text { Conflicting } \\
\text { - } & \text { Interest } \\
\text { - } & \text { Inappropriate gifts } \\
\text { - } & \text { Sexual } \\
\text { - } & \text { harassment } \\
& \text { Unauthorized } \\
& \text { payment } \\
\text { - } & \text { Affirmative actions } \\
\text { - } & \text { Employee privacy } \\
\text { - } & \text { Environmental } \\
& \text { issues }\end{array}$}} & $\begin{array}{l}\text { Organizational } \\
\text { culture }\end{array}$ & \multirow{5}{*}{$\begin{array}{ll}\text { - } & \text { Influencing } \\
& \text { employee } \\
& \text { behavior } \\
\text { - } & \text { Upholding } \\
& \text { corporate image } \\
\text { - } & \text { Building } \\
& \text { Relationship } \\
\text { - } & \text { Incorporating } \\
& \text { Ethical Code }\end{array}$} & $\begin{array}{l}\text { Strong Ethical } \\
\text { dilemma }\end{array}$ & \multirow{5}{*}{$\begin{array}{ll}- & \text { Creating } \\
\text { misconception } \\
\text { - } \\
\text { - Avoidance in } \\
\text { inherent ability } \\
\text { intellectual } \\
\text { - } & \text { Employee } \\
\text { behavior } \\
\text { remain } \\
\text { inconsistent } \\
\text { - Affecting } \\
\text { institutional } \\
\text { interest }\end{array}$} \\
\hline ICC & & & Beliefs & & $\begin{array}{l}\text { Inability to } \\
\text { handle }\end{array}$ & \\
\hline ILO & & & Values & & $\begin{array}{l}\text { Un-uniform } \\
\text { code of } \\
\text { business } \\
\text { Ethics }\end{array}$ & \\
\hline \multirow[t]{2}{*}{ CTC } & & & $\begin{array}{l}\text { Employee } \\
\text { perceptions }\end{array}$ & & \multirow[t]{2}{*}{$\begin{array}{c}\text { Unpredictable } \\
\text { situations }\end{array}$} & \\
\hline & & & Potent tools & & & \\
\hline
\end{tabular}

OECD : Organization for Economic Cooperation and Development

ICC : International Chamber of Commerce

ILO : International Labour Organisation

CTC : Center for Transnational Corporation

At the helm of diversities of international organizations a standardized ethical code featuring salient aspects of business can be formulated for enforcement of universal code of ethics focusing on multivariate business situations across nations. A prime ethical code designed exclusively to handle multicultural, multinational, multilingual dilemmas at the background of international business bodies is a requisite in the coming years ahead.

\section{Findings And Discussion}

From the literature explicate in the paper a clear attempt can be made to identify the items underlying the proposed "BESQ" scale. The five broad domains 
identified are discovering goals \& ethics, diversity management and ethics, entity value on decision making, legal perspective on business ethics and diversified ethics and gender differentiation. The basis of the creation of this scale has been literature review in the areas of discovering goals \& ethics, diversity management and ethics, entity value on decision making, legal perspective on business ethics and diversified ethics and gender differentiation.

The scale may be considered to have five broad domains -
A. Discovering goals \& ethics,
B. Diversity management and ethics,
C. Entity value on decision making,
D. Legal perspective on business ethics
E. Diversified ethics and gender differentiation

Each of the above domains con be independently considered to arrive at a handful of items for the scale. The items have been generated from a detailed literature study which has been a significant part of this paper. The following items can be comprehended as -

\section{Domain A: Discovering Goals \& Ethics}

A.1 The organization is goal directed \& looks into people management through MBO approach.

A.2 The organization allows individuals to be self merged with ethical ideologies.

A.3 There is a culture of idealistic employee behavior towards goal orientation.

A.4 Performance of employees is monitored by way of the goal oriented culture of the enterprise.

A.5 The enterprise successfully connects individual employees with the ethical worth.

\section{Domain B: Diversity Management \& Ethics}

B.1 Organisational excellence is measured in terms of employee efficiency and productivity.

B.2 There is a perfect blend of diverse value systems and a sound working climate in the enterprise.

B.3 Workforce contribution is measured both in the qualitative and quantitative manner.

B.4 Gratification of human rights is a key measure in diversity management in the organization.

B.5 There is equitable recognition of all employees in diversified situation based on fairness.

\section{Domain C: Entity Value on Decision Making}

C.1 The organization takes care in selection of the proper course of action from any abundant available alternative.

C.2 Individual self esteem is allowed to take the shape of a valuable component within the organisational operational process.

C.3 The enterprise climate easily transforms individual entity into group intergration.
C.4 The organization exchanges mutual
collaboration.

C.5 Value system and value structures are very pertinent in the context of any judicious decision making situation in the enterprise.

\section{Domain D: Legal Perspective on Business Ethics}

D.1 Business operations within the enterprise effectively follow all necessary legal bindings.

D.2 The legal age of the workplace acts as a protection and defending shield against all necessary immoral courses of actions detrimental for human advancement.

D.3 The principles of corporate governance are maintained through proper moral outlook and righteous way of business function in the organization.

D4. Truthfulness and Integrity are the pillars of all professional and personal relationship in the enterprise.

D5. There are necessary rewards for ethical performance of employees.

\section{Domain E: Diversified Ethics and Gender Differentiation}

E1. There is no discrimination and difference and there is complete culture of unified integration in the workplace.

E2. Management takes care towards harmonization of conflicting interest and maintaining employee privacy.

E3. Sexual harassment is strictly considered as a severe misconduct in the workplace.

E4. The organization encourages building relationship through responsibility sharing at work.

E5. The ultimate forces of the organization is the uphold the corporate image of the enterprise through effective diversity management.

\section{Conclusion}

This paper is therefore a humble attempt of the authors to delineate the domains and items under each domain towards creation of proposed scale to measure business ethics \& related practices for sustainable quality within an organization. The BESQ scale would thus focus on signifying the relevance of ethical business practices for globally sustainable organisational development.

The identified domain and related items derived from extensive literature review in the paper would lead to follow up research in this regard. This implies moving on for reliability and validity testing of the items towards justification of each of the items in relation to the proposed scale. This is the future direction of the study towards making the BESQ scale full proof. This paper therefore is a footing towards generating sustainable future for enterprises keeping ethical management practices in mind. 


\section{BIBLIOGRAPHY}

1. Alexander, J. M., \& Buckingham, J. (2011). Common good leadership in business management, an ethical model from the Indian tradition Business Ethics: An European Review.

2. Brenner, S. N. (1992). Ethics programs and their dimensions: Journal of Business Ethics.

3. Brody, L. R., \& Hall, L. A. (1993). Gender and Emotion Handbook of Emotions: New York Geulford Press.

4. Duncan, N. E., \& Wack, P. (1994). Scenarios Designed to Improve Decision Making: Strategy and Leadership, 22.

5. Forsyth, D. R. (1981).Moral Judgment: The influence of ethical ideology: Personality and Social Psychology.

6. Gamble, P. R., \& Gibson, D. A. (1999). Executive Values and Decision Making The Relationship of Culture and Information Flows: Journal of Management Studies, 36.

7. Gentile, M. C. (1998). Managing Excellence through Diversity: Illinois Waveland Press Inc.

8. Glenn, J. R. Jr. (1992). Can a Business and Society Course Affect the Ethical Judgment of Future Managers? : Journal of Business Ethics.

9. Kumar, Harish. (2003). Human Resource Management in the $21^{\text {st }}$ Century: anmol Publications Pvt. Ltd., New Delhi.

10. King, A. M., \& Gordon, A. H. (1998). Sex Differences in Emotion: Expression, Experience and Physiology: Journal of Personality and Social Psychology.

11. Linda, Klebe. Trevino. et. al. (1999). Managing Ethics and Legal Compliance: What works and What Hurts: Calcutta Management Review.

12. Miceli, M. P. \& Near, J. P. (2001). Ethical issues in the management of human resources: Human Resource Management Review.

13. Robertson, C., \& P. A. Fadil. (1999). Ethical Decision Making in Multinational Organisations A Culture Based Model: Journal of Business Ethics.

14. Seijts, G. H., \& Latham, G. P. (2005). Learning versus performance goals: When should each be used?: Academy of Management Executive.

15. Sakoni, R. (2012). Ethnic Diversity and Unity: The Nation, 06.

16. Urdan, T. (1997). Achievement goal theory Past results, future directions: Advances in Motivation and Achievement.

17. Vickers, M. (2005). Business ethics and the HR role Past, present and future: Human Resource Planning.

18. Wimbush, J. C., \& Shephard, J. M. (1984). Toward an Understanding of Ethical Climate, Its Relationship to Ethical Behavior and Supervisory Influence: Journal of Business Ethics.
19. Weaver, G. R., \&Trevino, L. K. (2001). The role of human resources in ethics/compliance management, a fairness perspective: Human Resource Management Review. 